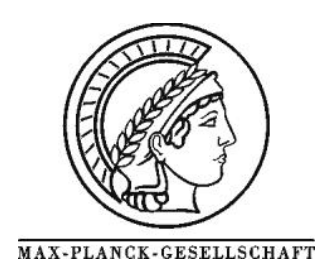

\title{
Controlling the yield and structure of carbon nanofibers grown on a nickel/activated carbon catalyst
}

\author{
A. Rinaldi ${ }^{\mathrm{a}, \mathrm{b}}$, N. Abdullah ${ }^{\mathrm{a}}$, M. Ali ${ }^{\mathrm{a}}$, A. Furche, S. B. Abd. Hamid ${ }^{\mathrm{a}}$, D. S. Su ${ }^{*}$, R. Schlögl ${ }^{\mathrm{b}}$ \\ ${ }^{a}$ Combicat University Malaya, Kuala Lumpur 50603, Malaysia \\ ${ }^{b}$ Fritz-Haber-Institut der Max-Planck-Gesellschaft, Faradayweg 4-6 Berlin, 14195, Germany \\ "Corresponding author: e-mail dangsheng@ fhi-berlin.mpg.de, Fax: +493084134405
}

Received 9 April 2009, Accepted 28 June 2009, Available online 2 July 2009

\begin{abstract}
Carbon nanofibers (CNFs) were grown via the chemical vapor deposition of $\mathrm{C}_{2} \mathrm{H}_{4}$ on an activated carbon (AC)-supported Ni catalyst. The texture of the CNF/AC composites can be tuned by varying the growth temperature and by treatment in reducing atmosphere prior to $\mathrm{C}_{2} \mathrm{H}_{4} / \mathrm{H}_{2}$ exposure. The Ni-catalyzed gasification of the AC support increases the microporosity of the composite and shown to be dominant throughout the composite synthesis especially during reduction, subsequent treatment in reducing atmosphere, and CNF growth at low temperatures. $\mathrm{N}_{2}$ isotherm and scanning electron microscope were used to characterize the texture and morphology of the composites. Subsequent treatment in reducing atmosphere were shown to increase the Ni catalyst activity to grow CNFs. High resolution transmission electron microscope however did not reveal any microstructural difference for $\mathrm{Ni}$ catalyst with and without the subsequent reduction treatment. We propose in this paper that the carbon dissolutions during treatment of the catalyst might have an implication on the CNF growth.
\end{abstract}

\section{Introduction}

Carbon materials possess unique characteristics, as they can exist in different forms that exhibit various functionalities. These materials range from $\mathrm{sp}^{2}$-hybridized graphitic materials, such as graphite, carbon nanofibers (CNFs) and carbon nanotubes (CNTs), to turbostratic carbons consisting of $\mathrm{sp}^{2}$ and $\mathrm{sp}^{3}$ mixtures such as carbon black, soot and activated carbons, to the $\mathrm{sp}^{3}$-hybridized diamond. The different allotropes offer a broad range of physical and chemical properties.

Application of carbon materials as catalyst supports have been widely reported with a broad scope of reaction applications [1-22]. As a support, activated carbon (AC) has attracted much interest because it offers advantages such as high thermal stability, high surface area, and cheap and easy recovery of the metal catalyst by simple combustion. Carbon-carbon composites may represent combinations of carbons having different dimensions (nano with micro) and/or different orderings (graphitic or disordered). $\mathrm{Su}$ et al. has successfully synthesis CNFs on AC support with $\mathrm{Fe}$ catalyst using $\mathrm{C}_{2} \mathrm{H}_{4}$ as the carbon source [23,24]. Such composites have found applications both as adsorbents and in catalysis [3-22].

During the past several years, metal-free catalysts have attracted considerable interest, especially in industrial application. However, only graphitic nanocarbons exhibit excellent long-term stability and high catalytic activity $[25,26]$. On the other hand, the powdery form of nanocarbons makes them unsuitable for use in fixed-bed reactors on an industrial scale. The compactions of loose nanocarbons used in previous work, before being transferred into the reactor, were evidence of severe technical difficulties. Therefore, immobilizing the graphitic nanocarbons onto a carbon-based support allows for better reactants diffusion, and prevents hot spots, pressure drops and avoiding chemical discontinuities in such a carbon-carbon composite [27]. Considering the issues described above, mass production of immobilized nanocarbons on a carbon support is desirable for industrial applications in chemical reactors.

Filamentous carbon was already reported in the late 1960s as side products in the petroleum and nuclear indus- 
tries, which caused severe technical problems. Various forms and microstructures of filamentous carbon were reported to deposit on metal surface after exposure to carboncontaining gases within a broad range of temperature from 323 to $1000^{\circ} \mathrm{C}$. Thus the early works related to carbon filaments was to control their formation aiming to prevent the carbon deposition $[28,29]$. The characterization of the carbon filament and the quantification of both the solid and gaseous product under reaction condition were carried out by the pioneering work of Alstrup and Baker for the study of steam reforming catalysis and in situ TEM works respectively. Based on kinetics and microstructural studies, it was proposed that the growth of carbon filaments process via the diffusion of carbons in the bulk of catalyst particles due to thermal and/or concentration gradients [29-33]. The investigation of carbon filaments further attracts researchers with the advent of high-resolution microscopy followed by the discovery of CNTs by Iijima [34,35]. Thus numerous papers arise with respect to the synthesis and applications of filamentous carbon materials. The aim of the present article is the large-scale synthesis of CNFs via the catalytic decomposition of $\mathrm{H}_{2}$ and $\mathrm{C}_{2} \mathrm{H}_{4}$ over an ACsupported Ni catalyst. Nickel was selected as the catalyst due to its higher activity in producing filamentous carbon compared to $\mathrm{Fe}$ and $\mathrm{Co}$ as the classic catalysts for $\mathrm{CNF}$ and CNT synthesis [36]. Pham-Huu et al. [37,38] synthesized CNFs using both graphite felt and CNTs as supports. These works produced uniform CNFs with herringbone and a mixture of herringbone and platelet graphene arrangements for systems supported on graphite felt and CNTs, respectively. However, these expensive support materials limit their use for industrial application. Thus, natural AC is a good alternative due to its low cost, availability in several shapes, and potential for chemical modification.

\section{Experimental}

\subsection{Catalyst impregnation}

The AC was derived from palm kernel shell obtained from NanoC sdn bhd. Malaysia. The AC was previously treated with concentrated $\mathrm{HNO}_{3}$ (70\%, Sigma Aldrich) to eliminate inorganic impurities, such as $\mathrm{Fe}$, that would lead to heterogeneity of the produced CNFs. Later in the text, $\mathrm{AC}$ is referred as the $\mathrm{HNO}_{3}$-treated support. The $\mathrm{AC}$ samples were ground and sieved to a $\leq 50 \mu \mathrm{m}$ particle size before impregnated via the wet-impregnation method with $\mathrm{Ni}\left(\mathrm{NO}_{3}\right)_{2}$ in an acetone solution to achieve Ni weight loading of $1 \%$. The samples were further dried overnight at $40^{\circ} \mathrm{C}$ in static air.

\subsection{CNF synthesis}

For every composite synthesis, 5 grams of the fresh catalyst were calcined at $250^{\circ} \mathrm{C}$ with $5 \% \mathrm{O}_{2}$ in $\mathrm{Ar}$ for 1 hour and reduced at $300^{\circ} \mathrm{C}$ under $5 \% \mathrm{H}_{2}$ in $\mathrm{Ar}$ for 1 hour. The temperature was then increased to the desired $\mathrm{CNF}$ growth temperature under $\mathrm{Ar}$ atmosphere. The $\mathrm{CNF}$ synthesis was carried out between $500^{\circ} \mathrm{C}$ and $850^{\circ} \mathrm{C}$ for 2 hours under a $\mathrm{H}_{2}$ and $\mathrm{C}_{2} \mathrm{H}_{4}$ gas mixture $(7: 1)$ with a total flow of 230 $\mathrm{ml} /$ minute. The calcination, reduction and CNT growth were carried out continuously in a single quartz tubular reactor. $\mathrm{CNF} / \mathrm{AC}$ composites synthesized at $500^{\circ} \mathrm{C}, 550^{\circ} \mathrm{C}$, $600^{\circ} \mathrm{C}, 700^{\circ} \mathrm{C}$ and $850^{\circ} \mathrm{C}$ from $1 \% \mathrm{Ni}$ supported on $\mathrm{AC}$ were designated as NC500, NC550, NC600, NC700 and NC850, respectively (Table 1). Composites synthesized with a subsequent treatment in $5 \% \mathrm{H}_{2}$ at $500^{\circ} \mathrm{C}$ and $550^{\circ} \mathrm{C}$ for 1 hour prior to $\mathrm{H}_{2}$ and $\mathrm{C}_{2} \mathrm{H}_{4}$ exposure are designated NCT500 and NCT550, respectively.

\subsection{Characterization methods}

The textural properties of the AC support and $\mathrm{CNF} / \mathrm{AC}$ composite were measured on the basis of the $\mathrm{N}_{2}$ isotherm performed at $77 \mathrm{~K}$ with a Quantachrome instrument. Surface area and micropore volume were calculated using the Dubinin-Radushkevich (DR) equation. The mesopore volume was determined as the difference between the total pore and micropore volume. The morphology of the CNFs was studied with a scanning electron microscope (SEM) performed on FEI Quanta 200F SEM. The quality and microstructure of the CNFs was investigated with a high resolution transmission electron microscope (HRTEM) performed on a Philips TEM/STEM LaB6 and FEG microscope. The acceleration voltage was set to $200 \mathrm{kV}$. CNF and CNT average diameter was calculated after measuring $200 \mathrm{CNFs}$ for every sample. The Ni particle size distribution was determined by counting 400 particles per sample. The temperature-programmed reduction (TPR) of the Ni/AC fresh sample was carried out under $5 \%$ $\mathrm{H}_{2}$ in $\mathrm{N}_{2}$ with a temperature ramping of $5^{\circ} \mathrm{C}$ per minute using a Netzcsh TG/SDTA coupled with an MS quadruple Omnistar detector. The weight change after each treatment was calculated by comparing the final weight with the impregnated sample's weight after water removal.

\section{Results and discussion}

\subsection{Texture and microstructure of the CNF/AC com- posites}

The textural properties of the reduced $\mathrm{Ni} / \mathrm{AC}$ samples and the CNF-AC composites produced at different temperatures are summarized in Table 1. In general, there is a gradual increase in the mesopore volume of the sample after reduction and after CNF growth. The $\mathrm{N}_{2}$ isotherms in Figure 1 show the appearance of hysteresis after CNF growth over the whole temperature range. Such $\mathrm{N}_{2}$ condensation at high relative pressure is assigned to the condensation in between the CNFs. Indeed, this observation is in 
Table 1. Textural properties of CNF/AC composites

\begin{tabular}{rcccccc}
\hline & Growth temp & $\begin{array}{c}\text { Weight change\% } \\
\text { after CNF growth }\end{array}$ & $\begin{array}{c}\text { DR Surface } \\
\text { area } \\
\mathrm{m}^{2} / \mathrm{g}\end{array}$ & $\begin{array}{c}\text { Micropore } \\
\text { volume } \\
\mathrm{cm}^{3} / \mathrm{g}\end{array}$ & $\begin{array}{c}\text { Total pore } \\
\text { volume } \\
\mathrm{cm}^{3} / \mathrm{g}\end{array}$ & $\begin{array}{c}\text { Mesopore } \\
\text { volume } \\
\mathrm{cm}^{3} / \mathrm{g}\end{array}$ \\
\hline AC & - & - & 1233 & 0.438 & 0.455 & 0.017 \\
Red 300 & - & -21 & 1454 & 0.517 & 0.565 & 0.048 \\
NC550 & - & -24.7 & 1485 & 0.527 & 0.585 & 0.058 \\
NC550 & 500 & -27 & nd & nd & 0.659 & 0.099 \\
NC600 & 550 & -10.3 & 1588 & 0.56 & 0.645 & 0.151 \\
NC700 & 700 & -2.6 & 1135 & 0.494 & 0.66 & 0.130 \\
NC850 & 850 & 16.2 & 1491 & 0.53 & 0.325 & 0.113 \\
NCT500 & 500 & 25 & 598 & 0.212 & 0.55 & 0.071 \\
NCT550 & 550 & -29 & 1347 & 0.479 & 0.725 & 0.183 \\
\hline
\end{tabular}

${ }^{\mathrm{a}}$ Subsequent reduction at $550^{\circ} \mathrm{C}$ for 1 hour $5 \% \mathrm{H}_{2} / \mathrm{Ar}$ after reduction at $300^{\circ} \mathrm{C}$

${ }^{\mathrm{b}}$ Not determined

agreement with our SEM images in Figure 2, which shows that the as grown CNFs are highly entangled, providing spaces for $\mathrm{N}_{2}$ molecules to condensate at high relative pressure. The NC500 sample showed no observable formation of CNF by SEM.

For composites synthesized at $550^{\circ} \mathrm{C}(\mathrm{NC550)}$ ) and $600^{\circ} \mathrm{C}(\mathrm{NC} 600)$, there is a positive relationship between the mesopore content and weight change (after CNF growth) (Table 1). At higher temperatures, however, the mesoporosity of the composites depended less on the CNF growth. This is mostly due to different level of CNF entanglement that occurs at different growth temperatures. CNFs grown at higher temperatures tend to give straighter filaments (Fig. 2d), most likely due to better graphene stacking of the CNF (Fig. 3). From HRTEM investigation presented in figure 3 , for $\mathrm{CNF}$ grown at $550^{\circ} \mathrm{C}$ the microstructure shows a poorly defined or hydrogenated amorphous carbon. Similar hydrogenated carbon filaments for growth at low temperature has been reported previously $[39,40]$. The CNF microstructures give defective platelets and more graphitic platelets when grown at $600^{\circ} \mathrm{C}$ and $700^{\circ} \mathrm{C}$ respectively. $\mathrm{CNFs}$ with parallel graphene wall perpendicular to the filament axis with hollow channel were observed for growth at $850^{\circ} \mathrm{C}$. $\mathrm{NC} 850$ give straight CNF morphology (Fig. 2d) showing less entanglement as featured in the $\mathrm{N}_{2}$ isotherm at a higher relative pressure (Fig. 1). The variation of the graphitic character of the samples under study was investigated by X-ray powder diffraction (Fig. 4). The Xray diffraction patterns did not show sharp graphite (002) and (100) signals for composites synthesized at low temperatures. Only the composite synthesized at $850^{\circ} \mathrm{C}$ showed appreciable intensity for the (002) diffraction signal, which might reflect the additive effect of both the improved graphitic character and the higher fraction of CNF (Fig. 3d and Table 1). None of the diffractograms of the composites
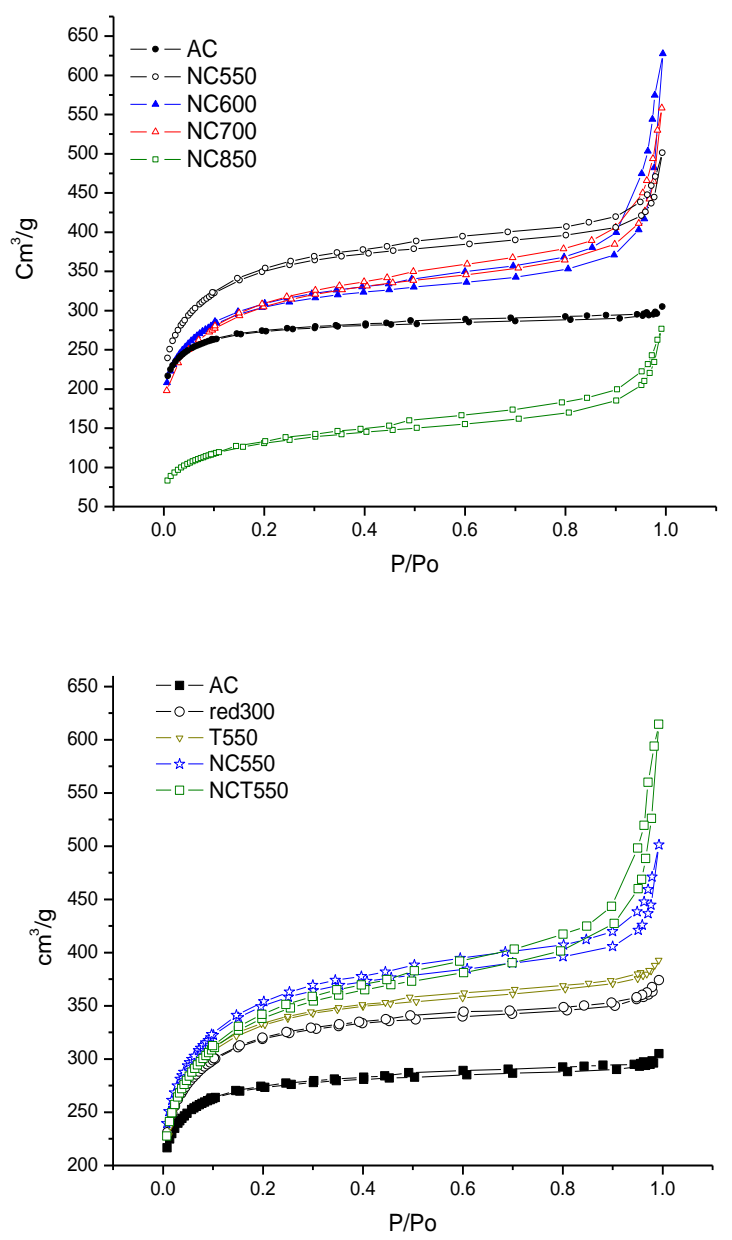

Fig. 1: $\mathrm{N}_{2}$ isotherm of the CNF/AC composites synthesized at different temperatures (a) and the effect of reduction and subsequent treatment to the to the $\mathrm{N}_{2}$ isotherm of $\mathrm{Ni} / \mathrm{AC}$ catalyst and CNF/AC composites (b). 

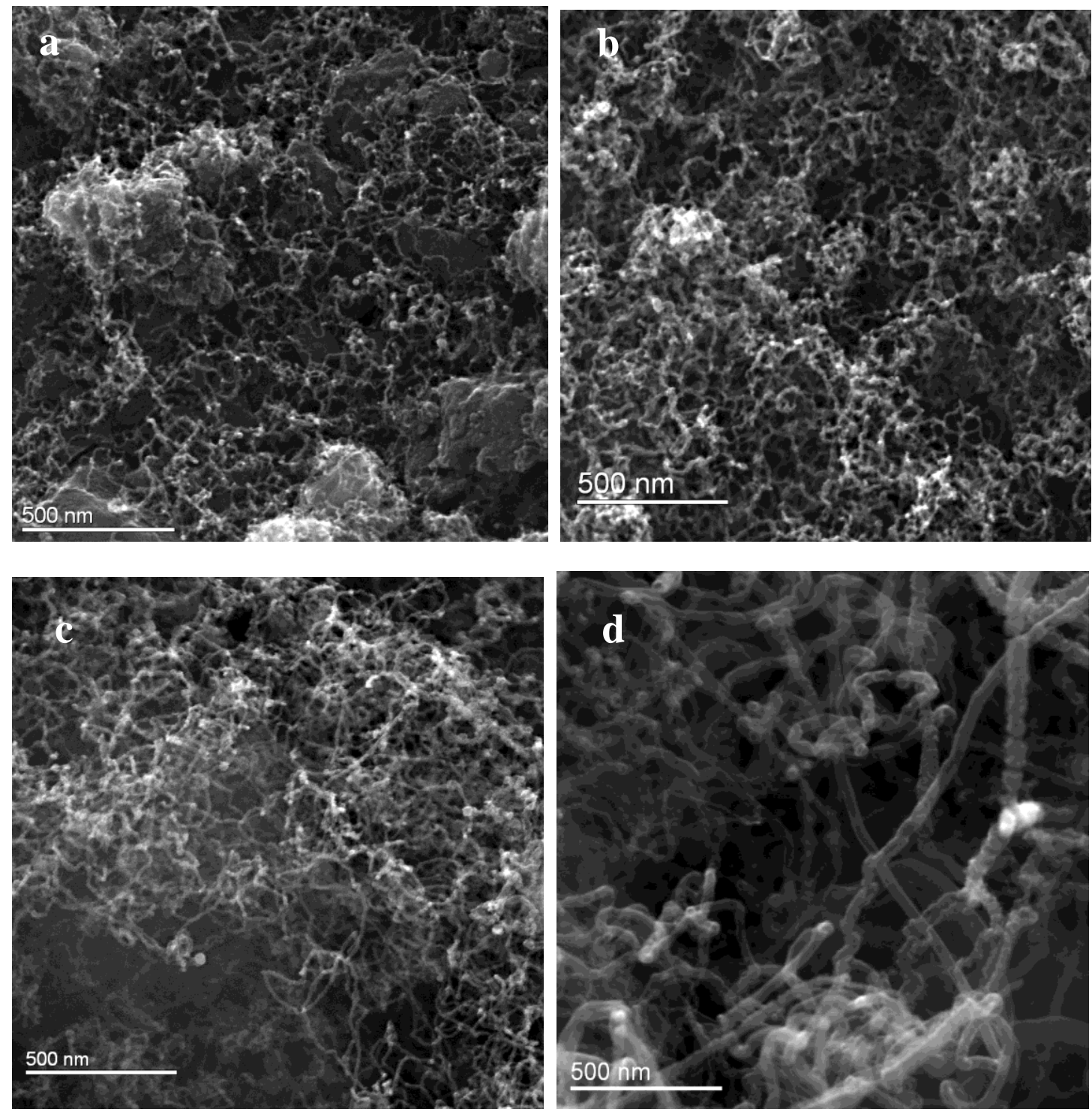

Fig. 2: SEM images of the CNF/AC composites: NC550 (a), NC600 (b), NC700 (c) and NC850 (d).

showed the presence of $\mathrm{Ni}$ metal or $\mathrm{Ni}$ carbide, possibly due to the low percentage of $\mathrm{Ni}$ in the composites.

The average $\mathrm{CNF}$ diameter in the composites was shown to increase with the synthesis temperature (Fig. 5). The increase may be primarily due to sintering of the $\mathrm{Ni}$ particles facilitated by the surface modifications (surface functional groups decomposition) of the AC supports. The average $\mathrm{CNF}$ diameter increased dramatically for composites synthesized at $850^{\circ} \mathrm{C}$. This behavior may also be due to the change in the growth mode from a mixture of octopus and single directional $\mathrm{CNFs}$ grown at $550-700^{\circ} \mathrm{C}$ to preferentially single direction CNFs for composite grown at $850^{\circ} \mathrm{C}$ (Fig. 3e and f). The octopus CNFs are mostly observed from bigger Ni particles, which is in agreement with previous studies [38,41-47]. Several effects, such as particle size, surface reconstructions, exposed facets and rate of ethylene decomposition, were proposed to explain the CNF growth preferences [48-51].
The octopus CNFs are beneficial for establishing a bulk macroscopic structure due to entanglement from multiple directions for each catalyst particle $[43,46]$.

\subsection{The catalytic gasification of $A C$ support by Ni catalyst}

Ni catalyzes the gasification of carbon supports under hydrogen [1,3,28,52-65]. As shown in Table 1 , the weight changes after growth indicate the extent of gasification during both reduction and $\mathrm{CNF}$ growth. The gasification is so dominant that the supported catalyst loses $20 \%$ of its mass after reduction. Figures $6 \mathrm{a}$ and $\mathrm{b}$ show the evolution of gaseous products from the Ni/AC catalyst during heating under inert gas (Ar) and 5\% $\mathrm{H}_{2} / \mathrm{Ar}$ respectively. In both cases the surface functional groups present on $\mathrm{AC}$ 

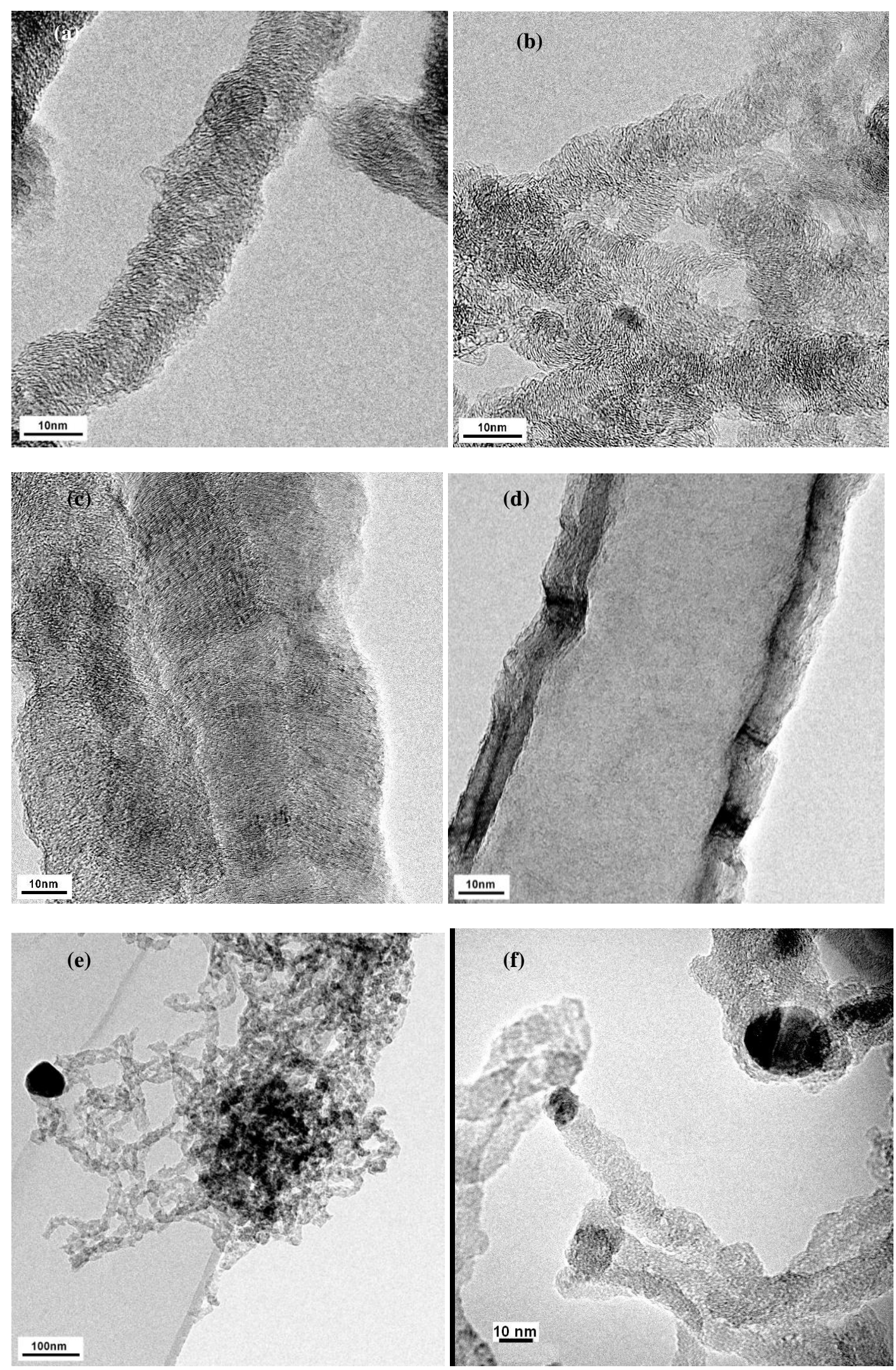

Fig. 3: Microstructure of CNF in NC550 (a), NC600 (b), NC700 (c), NC850 (d), octopus (e) and single directional CNF (f) typically present in $\mathrm{CNF} / \mathrm{AC}$ composites. 


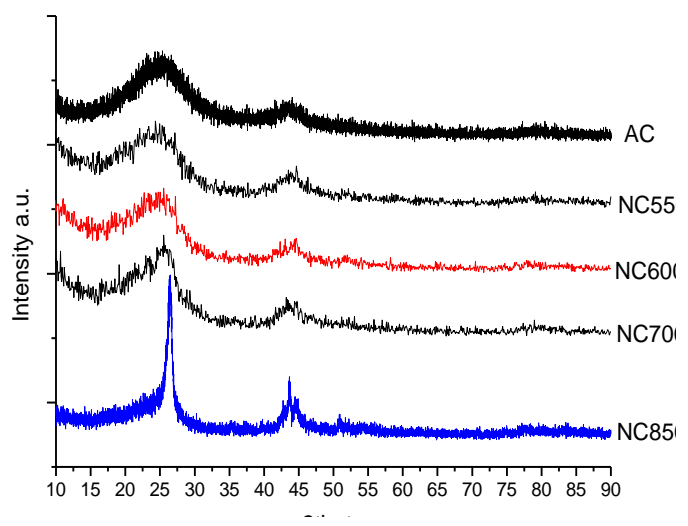

Fig. 4: XRD patterns of the $\mathrm{AC}$ and $\mathrm{CNF} / \mathrm{AC}$ composites.

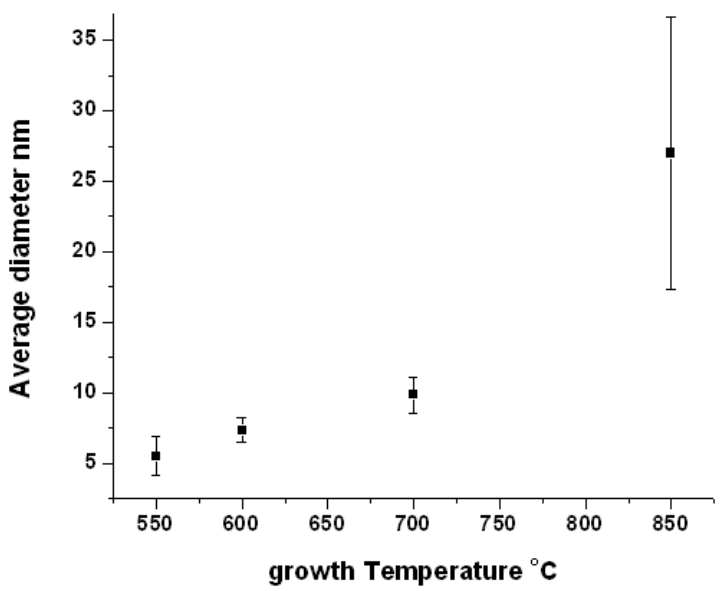

Fig. 5: Average diameters of CNF grown at different temperatures.

support decompose during heating $[1,3,66]$. Methane was only detected when the $\mathrm{Ni} / \mathrm{AC}$ catalysts were heated under reducing atmosphere. It is still unclear whether the catalytic gasification proceeds via spillover of hydrogen and/or gasification of carbon on the Ni surface as a result of carbon atoms diffusing from the metal-carbon support interface $[3,52,56]$.

Figure $6 \mathrm{~b}$ shows that methane starts to evolve at around $250^{\circ} \mathrm{C}$, which indicates the presence of $\mathrm{Ni}$ metal available to provide active hydrogen to gasify the AC support. The reduction process increases the micropore volume by $20 \%$ and gives a 3 -fold increase of the mesopore volume (Table 1). The knee broadening in the $\mathrm{N}_{2}$ isotherm at $\mathrm{P} / \mathrm{Po}$ $<0.2$ indicates broadening of the pore size distribution towards bigger pores, which could be explained by the catalytic gasification of the supports creating new pores and/or enlarge existing ones in the dimension of the Ni particle sizes (Fig. 1b). Because AC is microcrystalline curved graphite with possible cross-linking between the graphite microcrystals, the catalytic gasification is likely to occur in three dimensions of the carbon matrix, creating voids thus (a)

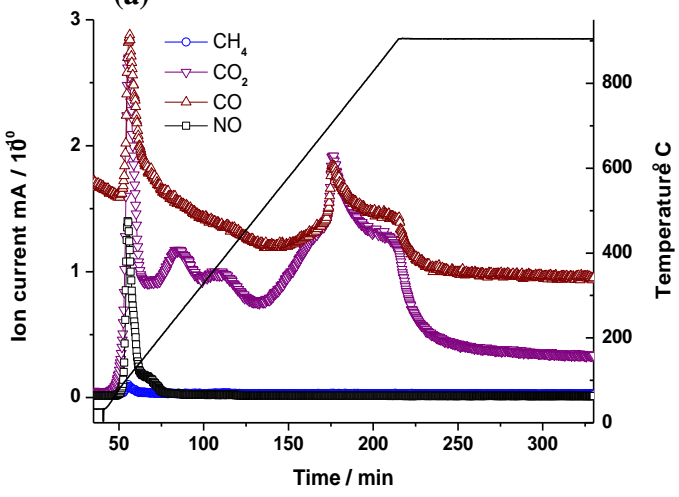

(b)

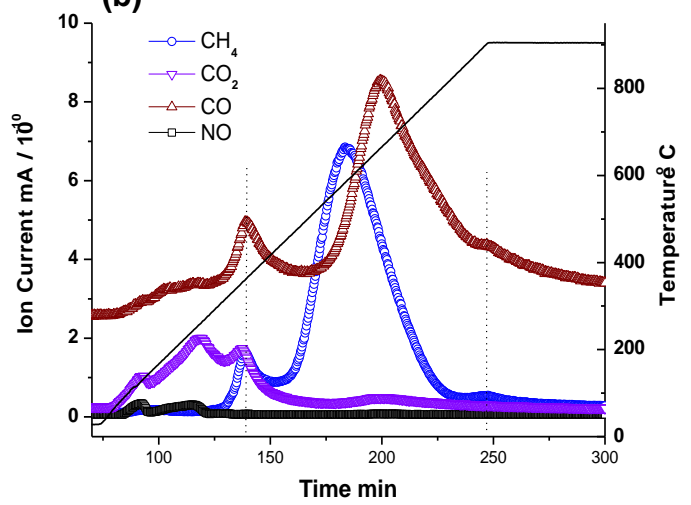

Fig. 6: Gasses evolved during the heat treatment in argon (a) and $5 \% \mathrm{H}_{2}$ in argon (b) of $1 \mathrm{wt} \% \mathrm{Ni} / \mathrm{AC}$

increasing the porosity. Such gasification is different from that of graphite that forms two-dimensional channels in certain directions [57-59,60,62,67]. Figure $1 \mathrm{~b}$ also shows that catalytic gasification remains a dominant process even after CNF growth, especially for composite grown at $550^{\circ} \mathrm{C}$. The preservation of microporosity in the composites, even after $\mathrm{CNF}$ growth for 5 hours, suggest that $\mathrm{Ni}$ catalysts of the micropores dimension $(\sim 2 \mathrm{~nm})$ may be inactive under these conditions. In fact, no filaments of $\sim 2$ $\mathrm{nm}$ in diameter were observed in the TEM images for any of the composites. Another possible scenario is that these $\mathrm{Ni}$ nanoparticles sinter to form bigger particles during the gasification prior to the growth of CNFs. Indeed, the catalyst size distributions measured for samples after reduction (red300) and after subsequent treatment at $550^{\circ} \mathrm{C}$ (T550) show a shift towards a higher value, indicating a tendency for the $\mathrm{Ni}$ particles to sinter after treatment at $550^{\circ} \mathrm{C}$ (Fig. 7). In an earlier study on Ni-catalyzed carbon gasification Tomita et al. reported the gradual increase of $\mathrm{Ni}$ particle size after the gasification in hydrogen atmosphere [54].

Gasification produces two prominent $\mathrm{CH}_{4}$ peaks, the first at the low temperature region with a peak maximum at $300^{\circ} \mathrm{C}$ and a second peak with higher intensity and a maximum around $670^{\circ} \mathrm{C}$. The methane production is strongly correlated with the surface functionalities of the carbon 

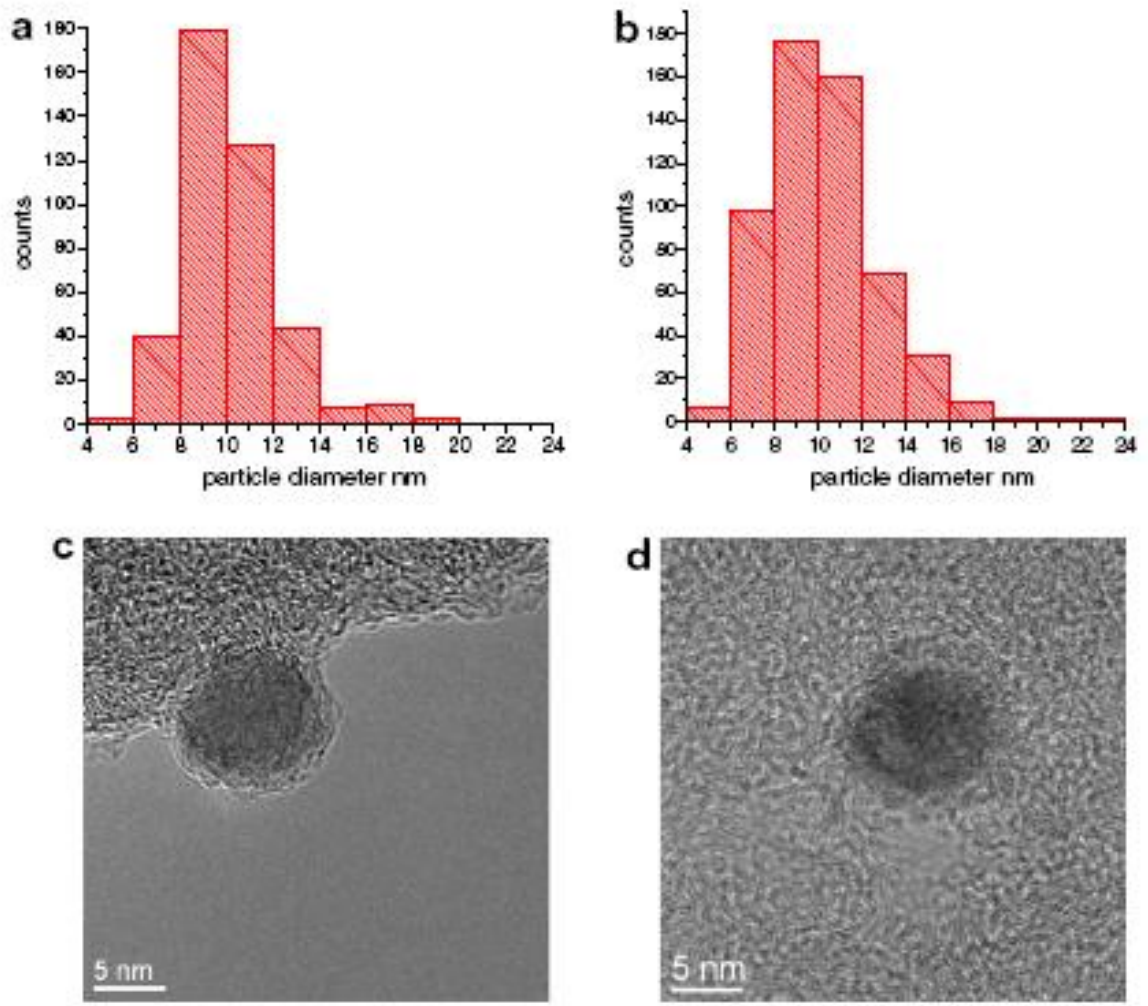

Fig. 7: Particle size counts and HRTEM for the Ni/AC catalyst after reduction ( $\operatorname{Red} 300)(a, c)$ and after subsequent treatment (T550) (b, d).

support [54]. Figure $6 \mathrm{~b}$ shows the overlapping $\mathrm{CH}_{4}$ and $\mathrm{CO}$ peaks at the low temperature region and deviated from the overlaps for the second methane peak at the higher temperature region. Note that $\mathrm{CO}_{2}$ evolution under reducing atmosphere was suppressed dramatically at the high temperature region. $\mathrm{CH}_{4}$ production decreased at around $750^{\circ} \mathrm{C}$, as shown in Figure $6 \mathrm{~b}$. The minimum is also illustrated in the $\mathrm{N}_{2}$ isotherms after reduction at $300^{\circ} \mathrm{C}$ and subsequent treatment at $550^{\circ} \mathrm{C}$ in Figure $1 \mathrm{~b}$. The isotherms show a more moderate increase in micropore adsorption for samples after subsequent treatment at $550^{\circ} \mathrm{C}$ when compared with that after reduction at $300^{\circ} \mathrm{C}$. Several arguments have been proposed from earlier studies to explain the catalytic gasification deactivation, which includes catalyst encapsulation by carbon, $\mathrm{H}_{2}$ diffusion problems, and catalystcarbon surface contact loss [52,54,56,63]

\subsection{The effect of the subsequent treatment to the CNF/AC composite}

Interestingly, the $\mathrm{CNF}$ growth increased dramatically with subsequent treatment at $500^{\circ} \mathrm{C}$ (NCT500) or $550^{\circ} \mathrm{C}$ (NCT550), compared if composites were synthesized without the treatment (NC500 and NC550) as represented in the SEM images shown in Figure 8. CNF was not observed under SEM analysis for sample grown at $500^{\circ} \mathrm{C}$ without the subsequent treatment (NC500). The effect of the treatment is reflected in the increased weight change, the develop- ment of the hysteresis in the $\mathrm{N}_{2}$ isotherm and thus higher mesoporosity after CNF growth (Table 1 and Fig. 1b).

In an attempt to understand the improved activity after the treatment at $550^{\circ} \mathrm{C}$, TEM investigations were carried out for $\mathrm{Ni} / \mathrm{AC}$ samples after reduction at $300^{\circ} \mathrm{C}(\operatorname{Red} 300)$ and after subsequent treatment at $550^{\circ} \mathrm{C}$ (T550) for their catalyst size distribution and microstructure (Fig. 7). Both size distributions and microstructure of $\mathrm{Ni}$ particles failed to show significant differences after either treatment. Within the resolution of the HRTEM used, the d spacing of the $\mathrm{Ni}$ particles show values assign for $\mathrm{Ni}^{0}$ with fcc structure. Albeit a small shift in the catalyst size distribution after the subsequent treatment, it is unlikely that such small difference can cause the dramatic activity for CNF growth. However, we have yet to take into consideration that the shape of Ni particle may changes after each treatment. Pioneering works with controlled atmosphere electron microscope (CAEM) by Baker in the 70s clearly showed the mobility of metal particles on graphite under different atmospheres [28,57,62,67-69]. Later on equipped with better resolution, Anton [64,65] also reported the liquid-like mobility of Ni nanoparticles on thin amorphous carbon films subjected to heating in inert and reducing atmospheres under in situ TEM observations at temperatures similar to the current study. The mobile Ni particles were observed to wet the carbon surface and spread out randomly leaving behind graphitic tracks. Thus, reshaping the Ni particles during reduction and subsequent treatment is very likely to occur in the current study. To elucidate on the mobility of 

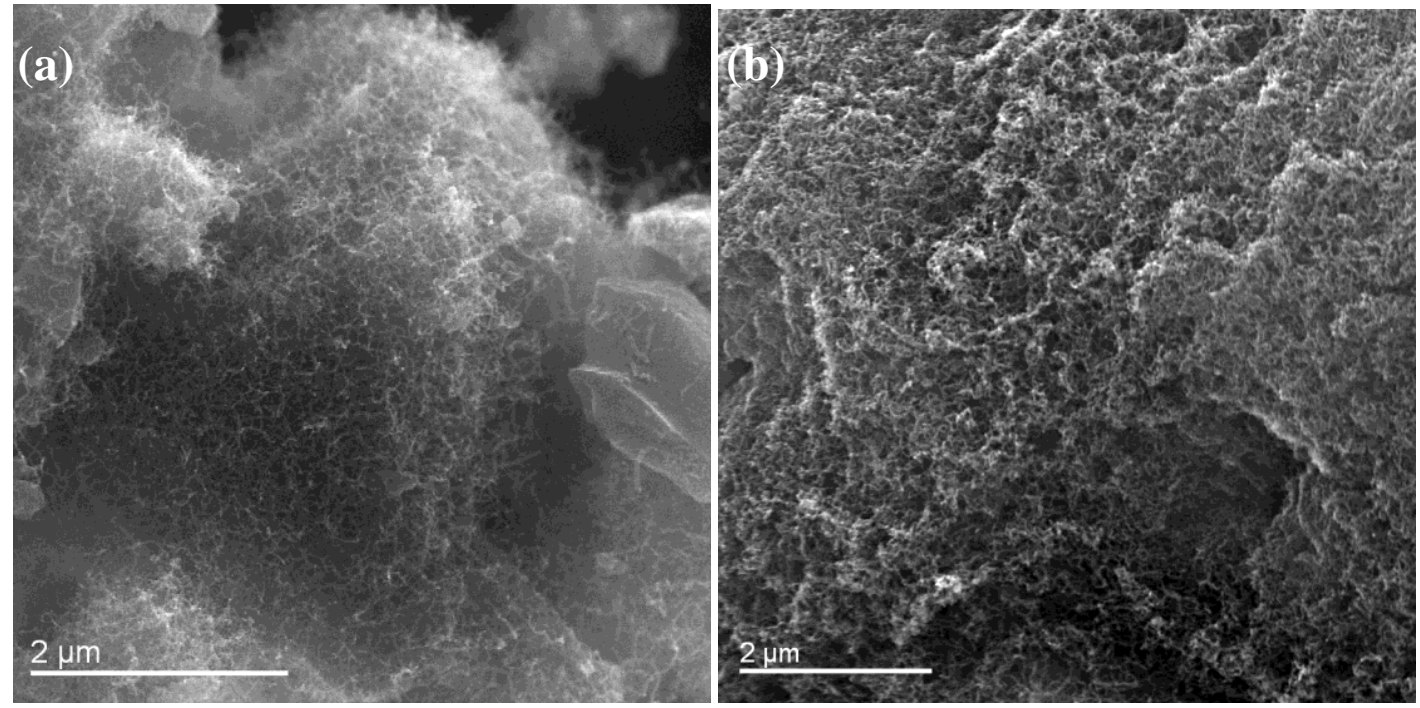

Fig. 8: SEM images of CNF/AC composites synthesized after treatment in $5 \% \mathrm{H}_{2} / \mathrm{Ar}$ for 1 hour at $500^{\circ} \mathrm{C}$ (NCT500) (a) and $550^{\circ} \mathrm{C}$ (NCT550) (b).

catalyst metal particles, Baker has shown the relationship between mobility of metal particles on graphite surface with the Tammann temperature $\left(0.5 \mathrm{~T}_{\text {melting }}\right)$ of the metal. For 10nm size Ni metal particles it was observed that the mobility starts at $640^{\circ} \mathrm{C}$ under hydrogen atmosphere $[62,67,69]$. The temperature is lower than that expected from the current investigation where the gasification and the increase of porosity were observed. This may be due to the smaller average size of Ni particle size (fig 7) and the nature of carbon support, which is less graphitic and more functionalized in the current study $[52,54,56]$. In addition the catalyst surface could be at a higher temperature due to the heat released from the gasification. Thus there is every reason to believe that the mobility will have a pronounced effect in the orientation and size distribution of the metal particles on the carbon surface.

In the previous in situ TEM study of Ni-catalyzed amorphous carbon gasification, Ni particles encapsulated with several graphitic layers were also observed. Indeed earlier works have shown under inert atmosphere iron and nickel supported on amorphous carbon films precipitated graphite films after heating [70,71]. However Ni particles encapsulated by graphitic layers or carbon layers were not observed by our HRTEM investigation of samples in the current study.

In addition, there is also a possibility for surface reconstruction of the Ni catalyst to occur due to the adsorption-desorption dynamics of $\mathrm{CH}_{4}$ and $\mathrm{CO}$ molecules during the two treatments [72-75]. The CO profile changed dramatically when the atmosphere was changed from $\mathrm{Ar}$ to $5 \%$ $\mathrm{H}_{2} / \mathrm{Ar}$, which strongly suggest that $\mathrm{CO}$ molecules interact with the Ni catalyst. TPR was carried out in a temperature program to simulate the reduction at $300^{\circ} \mathrm{C}$ and subsequent treatment at $550^{\circ} \mathrm{C}$ under $5 \% \mathrm{H}_{2} / \mathrm{Ar}$ atmosphere (fig. 9). The subsequent treatment at $550^{\circ} \mathrm{C}$ produced a significantly higher $\mathrm{CH}_{4}$ peak. Nevertheless, the catalyst particles are still in a metallic state after subsequent reduction at $550^{\circ} \mathrm{C}$, and no Ni carbide phase was evident in the HRTEM images (Fig. 7c and d). The absence of carbidic phase is expected, as $\mathrm{Ni}$ carbide is not stabile at $550^{\circ} \mathrm{C}$ [76]. Similarly the presence of metallic state and the absence of carbidic phase of $\mathrm{Ni}$ catalyst were previously reported after deactivation from the catalytic carbon support gasification, after graphitization of the amorphous carbon film, and during and after CNT growth [44,63,65,77-81]. Catalytic gasification, CNT and $\mathrm{CNF}$ growth, and catalytic graphitization presumably involve a similar general mechanism of carbon atoms dissolutions, diffusion and precipitation from the catalyst $\mathrm{Ni}$ particles $[56,65]$. However, several works have claimed the presence of dissolved carbon $[44,82]$ or carbide-like compounds [81] in Ni catalyst particles after CNF growth. Such dissolved carbon or carbon contamination has also been reported in works involving metal catalyst supported on non-graphitic carbons [1,83,84]. Gandia and Montes [85] reported the influence of carbon contamination of the carbon-supported $\mathrm{Ni}$ catalyst on the hydrogenation of acetone after thermal treatments in inert and $\mathrm{H}_{2}$ atmospheres.

Based on the TPR profiles in Figures $6 \mathrm{~b}$ and 9, $\mathrm{CH}_{4}$ and $\mathrm{CO}$ evolution may be interdependent on the surface of the Ni catalyst. Indeed, several surface carbon species have been identified from the $\mathrm{CO}$ hydrogenation reactivity of $\mathrm{Ni}$ catalysts at conditions similar to those in the current study [86]. Such surface carbons or surface carbidic species that may be present in the current study may cause electronic perturbations [74,87] and geometrical modifications $[73,88]$, and thus affecting the activity of the $\mathrm{Ni}$ catalyst. Based on the literature mentioned above, we suggest the possibility of dissolved and/or surface carbons in the bulk and/or surface of Ni particles after reduction and/or after the subsequent treatment that may contribute to the Ni catalyst activity for CNF growth. 


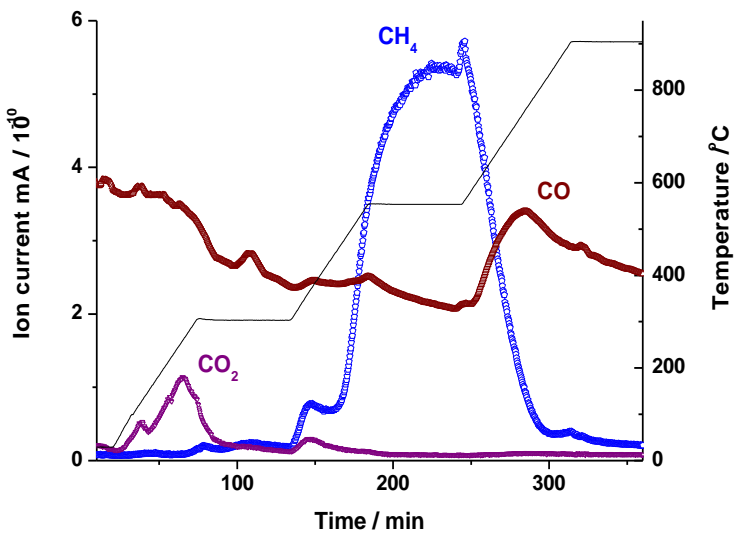

Fig. 9: Gasses evolved during TPR experiment under $5 \% \mathrm{H}_{2} / \mathrm{Ar}$ simulating reduction at $300^{\circ} \mathrm{C}$ and subsequent treatment at $550^{\circ} \mathrm{C}$.

Bengaard et al [89] demonstrated that certain facets or orientations in Ni particles are energetically more favored for carbon deposition. Based on earlier studies of metal catalyst on carbon support under heating and different gaseous environments, it is reasonable to believe that shape and/or orientation of the Ni catalyst particles in our study may change $[28,60,62,64,65,67,69,78,90]$. However, no conclusive differences were observed by standard HRTEM characterization in the current study for samples after reduction at $300^{\circ} \mathrm{C}$ and after subsequent treatment at $550^{\circ} \mathrm{C}$. (fig $7 \mathrm{c}$ and $\mathrm{d}$ ). The respective temperature and gas atmosphere conditions can give significant differences between the standard and the environmental TEM observations.

Metal catalysts supported on disorder carbon were shown to give lower activity than metal catalyst supported on graphitic carbons. In one of the early application of CNFs as catalyst support Rodriguez et al. have clearly shown the superiority of graphitic filament over disordered carbon support [5]. Various arguments were proposed previously to explain the intrinsic activity difference between metal catalyst supported on disordered and graphitic carbon. They include carbon contaminations, carbon encapsulation and faceting of the catalyst particles. Savva et al [91] reported that $\mathrm{Ni}$ supported on CNTs showed activity for $\mathrm{CNF}$ production with $\mathrm{C}_{2} \mathrm{H}_{4}$ at $400^{\circ} \mathrm{C}$, whereas Otsuka et al [92] showed that $\mathrm{Ni}$ supported on carbon fiber could grow herringbone $\mathrm{CNFs}$ after exposure to $\mathrm{C}_{2} \mathrm{H}_{4}$ at $500^{\circ} \mathrm{C}$. Other authors have also reported the production of CNFs by $\mathrm{Ni}$ supported on various carbon supports with $\mathrm{C}_{2} \mathrm{H}_{4}$ in similar temperature ranges as those used in our study [51,57]. Pham-Huu et al [38] reported that CNF-supported Ni catalysts could grow $\mathrm{CNFs}$ with $\mathrm{C}_{2} \mathrm{H}_{6}$ in similar temperature ranges.
In the current study, $550^{\circ} \mathrm{C}$ was the lowest temperature where CNFs can be observed with electron microscope after 1 hour reduction at $300^{\circ} \mathrm{C}$. In addition to the already complicated dynamics of the catalyst for CNT and CNF synthesis, the fact that $\mathrm{Ni}$ may be supplied with carbon from three different sources $\left(\mathrm{C}_{2} \mathrm{H}_{4}\right.$, carbon support and $\mathrm{CO}$ from the surface functionalities) further complicates the process. There are still no conclusive arguments for how gasification and/or carbon support contamination can change the catalyst activity to grow CNFs. Nevertheless, we showed experimentally that subsequent treatment of $\mathrm{Ni} / \mathrm{AC}$ under reducing atmosphere for 1 hour prior to $\mathrm{C}_{2} \mathrm{H}_{4}$ and $\mathrm{H}_{2}$ exposure increases the ability of the system to grow CNFs significantly.

We suggest several possible scenarios to explain the additional activity of the $\mathrm{Ni}$ catalyst after the subsequent treatment process: the presence of dissolved carbon, surface carbon, surface carbide, catalyst faceting and reconstruction, which may all contribute to the increase in $\mathrm{Ni}$ catalyst activity in growing CNFs under the current conditions. Such activity enhancement may also be relevant for the study of other reactions involving $\mathrm{CO}$ and/or hydrocarbons.

\section{Conclusions}

CNFs and CNTs have been synthesized using a $\mathrm{Ni} / \mathrm{AC}$ catalyst. By varying the growth temperature, the microstructure and the texture of the CNF/AC composite have been successfully controlled. Catalytic gasification was experimentally shown to change the texture of the $\mathrm{CNF} / \mathrm{AC}$ composites via the development of microposrosity. For composites synthesized at low temperatures, the activity of the $\mathrm{Ni} / \mathrm{AC}$ catalyst was increased significantly after treatment with $5 \% \mathrm{H}_{2} / \mathrm{Ar}$ prior to $\mathrm{C}_{2} \mathrm{H}_{4} / \mathrm{H}_{2}$ exposure. However, the particle size distribution and the microstructure of the Ni catalyst after the treatment did not show appreciable changes.

\section{Acknowledgements}

The work in Berlin is partly supported by Enerchem framework of Max-Planck Society. We gratefully acknowledged the contributions of Wiebke Frandsen and Norbert Pfander for acquiring TEM images, Andrew Yakin Sinit for SEM images, Rostam Omar for surface area measurements and Dr Jean-Philippe Tessonnier, Dr Di Wang and Dr Thomas W. Hansen and Dr Lidong Shao for fruitful discussions. 


\section{References}

[1] Schlögl R. Carbons. In: Ertl G, Knözinger H, Schüth F, Weitkamp J, editors. Handbook of Heterogeneous Catalysis, vol. 3. Weinheim: Wiley-VCH; 2008. pp. 357-427.

[2] Bae SD, Sagehashi M, Sakoda A. Activated carbon membrane with filamentous carbon for water treatment. Carbon 2003;41(15):2973-9.

[3] Reinoso FR. The role of carbon materials in heterogeneous catalysis, Carbon 1998;36(3):159-75.

[4] Bouwens SMAM, van Veen JAR, Konigsberger DC, de Beer VHJ, Prins R. Extended X-ray absorption fine structure of the structure of Cobalt on Carbon-supported Co and Co-Mo sulfide hydrodesulfurization catalysts. J Phys Chem 1991;95: 123-134.

[5] Rodriguez NM, Kim MS, Baker RTK. Carbon nanofibers: a unique catalyst support medium. J Phys Chem 1994; 98: 13108-11.

[6] Kowalczyk Z, Jodzis S, Raróg W, Zielinski J, Pielaszek J, Presz A. Carbon-supported ruthenium catalyst for the synthesis of ammonia. The effect of the carbon support and barium promoter on the performance. Appl Catal A 1999;184(1):95102.

[7] Kowalczyk Z, Sentek J, Jodzis S, Diduszko R, Presz A, Terzyk A, et al. Thermally modified active carbon as a support for catalysts for $\mathrm{NH}_{3}$ synthesis. Carbon. 1996 ;34(3):403-9.

[8] Reshetenko TV, Avdeeva LB, Ismagilov ZR, Chuvilin AL. Catalytic filamentous carbon as supports for nickel catalysts. Carbon. 2004 ;42(1):143-8

[9] Dandekar A, Baker RTK, Vannice MA. Carbon-Supported Copper Catalysts: I. Characterization. J Catal 1999;183(1):131-54.

[10] Albers P, Burmeister R, Seibold K, Prescher G, Parker SF, Ross DK. Investigations of Palladium Catalysts on Different Carbon Supports. J Catal 1999;181(1):145-54.

[11] Chambers A, Nemes T, Rodriguez NM, Baker RTK. Catalytic Behavior of Graphite Nanofiber Supported Nickel Particles. 1. Comparison with Other Support Media. J Phys Chem B 1998;102(12):2251-8.

[12] Dandekar A, Baker RTK, Vannice MA. Carbon-Supported Copper Catalysts: II. Crotonaldehyde Hydrogenation. J Catal 1999;184(2):421-39.

[13] Salman F, Park C, Baker RTK. Hydrogenation of crotonaldehyde over graphite nanofiber supported nickel. Catal Today 1999;53(3):385-94.

[14] Pham-Huu C, Keller N, Ehret G, Charbonniere LJ, Ziessel R, Ledoux MJ. Carbon nanofiber supported palladium catalyst for liquid-phase reactions: An active and selective catalyst for hydrogenation of cinnamaldehyde into hydrocinnamaldehyde. J Mol Catal A: Chemical. 2001;170(1-2):155-63.

[15] Baker RTK, Laubernds K, Wootsch A, Paál Z. Pt/Graphite Nanofiber Catalyst in n-Hexane Test Reaction. J Catal 2000;193(1):165-7.

[16] Gurrath M, Kuretzky T, Boehm HP, Okhlopkova LB, Lisitsyn AS, Likholobov VA. Palladium catalysts on activated carbon supports: Influence of reduction temperature, origin of the support and pretreatments of the carbon surface. Carbon. $2000 ; 38(8): 1241-55$

[17] Ros TG, Keller DE, van Dillen AJ, Geus JW, Koningsberger DC. Preparation and Activity of Small Rhodium Metal Particles on Fishbone Carbon Nanofibres. J Catal 2002;211(1):85102.
[18] Liang C, Li Z, Qiu J, Li C. Graphitic Nanofilaments as Novel Support of Ru-Ba Catalysts for Ammonia Synthesis. J Catal;211(1):278-82

[19] Wu G, Chen Y, Xu B. Remarkable support effect of SWNTs in $\mathrm{Pt}$ catalyst for methanol electrooxidation. Electrochem Commun 2005;7(12):1237-43.

[20] Toebes ML, Zhang Y, Hájek J, Alexander Nijhuis T, Bitter JH, Jos van et al. Support effects in the hydrogenation of cinnamaldehyde over carbon nanofiber-supported platinum catalysts: characterization and catalysis. J Catal 2004;226(1):21525.

[21] Zhang A, Han D, Zhu Z, Lee J, Rhee H. Synthesis and catalytic application of $\mathrm{Ni}$-supported carbon nanotubes for $\mathrm{n}$ heptane cracking. Korean J Chem Eng 2003;20(4):649-52.

[22] Bahome MC, Jewell LL, Hildebrandt D, Glasser D, Coville NJ. Fischer-Tropsch synthesis over iron catalysts supported on carbon nanotubes. Appl Catal A: General. 2005;287(1):60-7.

[23] Su DS. Chen X, Wienberg G, Hofmann AK, Timpe O, Abd Hamid SB, et al. Hierarchically structured carbon: Synthesis of carbon nanofibers nested inside or immobilized onto modified activated carbon. Angew Chem Int Ed 2005;44(34):5488-92.

[24] Chen X, Su D, Hamid SBA, Schlogl R. The morphology, porosity and productivity control of carbon nanofibers or nanotube on modified activated carbon. Carbon 2007;45(4):892-902.

[25] Mestl G, Maksimova NI, Keller N, Roddatis VV, Schlogl R. Carbon nanofilaments in heterogeneous catalysis: an industrial application for new carbon material. Angew Chem Int Ed 2001;40(11):2066-8.

[26] Su DS, Maksimova N, Delgado JJ, Keller N, Mestl G, Ledoux ML, et al. Nanocarbon in selective oxidative dehydrogenation reaction. Catal Today 2005;102-103:110-4.

[27] Delgado JJ, Vieira R, Rebmann G, Su DS, Keller N, Ledoux $\mathrm{ML}$, et al. Immobilized carbon nanofiber as industrial catalyst for ODH reaction. J Catal 2006;244(1):126-9.

[28] Baker RTK, Harris PS. The formation of filamentous carbon. In: Walker Jr. PL, Thrower PA, editors. Chemistry and physics of carbons, vol. 14. New York: Marcel Dekker Inc.; 1978. pp. 83-165.

[29] Rostrup-Nielsen JR. Steam reforming catalysts. Copenhagen: Teknisk Forlag. 1975: 127-149.

[30] Baker RTK, Harris PS, Thomas RB, Waite RJ. Formation of filamentous carbon from iron, cobalt and chromium catalyzed decomposition of acetylene. J Catal 1973;30(1):86-95.

[31] Alstrup I. A new model explaining carbon filament growth on nickel, iron, and $\mathrm{Ni}-\mathrm{Cu}$ alloy catalysts. J Catal 1988;109(2):241-251.

[32] Rostrup-Nielsen J, Trimm DL. Mechanisms of carbon formation on nickel-containing catalysts. J Catal 1977;48(1-3):155165.

[33] Snoeck J-, Froment GF, Fowles M. Filamentous Carbon Formation and Gasification: Thermodynamics, Driving Force, Nucleation, and Steady-State Growth. J Catal 1997;169(1):240-9.

[34] Iijima S. Helical microtubules of graphitic carbon. Nature. $1991 ; 35: 56-58$.

[35] Iijima S, Ichihashi T. Single-shell carbon nanotubes of 1-nm diameter. Nature. 1993;363:603-5.

[36] Yamada Y, Hosono Y, Murakoshi N, Higashi N, Ichi-oka H, Miyake $\mathrm{T}$, et al. Carbon nanofiber formation on iron group 
metal loaded on $\mathrm{SiO}_{2}$. Diamond Relat Mater 2006;15(48):1080-4.

[37] Vieira R, Pham-Huu C, Keller N, Ledoux MJ. New carbon nanofiber/graphite felt composite for use as a catalyst support for hydrazine catalytic decomposition. Chem Comm 2002;9:954-5.

[38] Pham-Huu C, Keller N, Roddatis VV, Mestl G, Schlogl R, Ledoux MJ. Large scale synthesis of carbon nanofiber by catalytic decomposition of ethane on nickel nanocluster decorating carbon nanotubes. Phys Chem Chem Phys 2002;4(3):514-21.

[39] Vander Wal RL, Ticich TM, Curtis VE. Directed synthesis of metal-catalyzed carbon nanofibers and graphite encapsulated metal nanoparticles. J Phys Chem B 2000;104(49):11606-11.

[40] Aoki K, Yamamoto T, Furuta H, Ikuno T, Honda, S, Furuta $\mathrm{M}$, et al. Low temperature growth of carbon nanofiber by thermal chemical vapor deposition using CuNi catalyst. Jpn J Appl Phys 2006;45(6A):5329-31.

[41] Monthioux M, Noe L, Dussault L, Dupin J-C, Latorre N, Ubieto $\mathrm{P}$, et al. Texturising and structurising mechanisms of carbon nanofilaments during growth. J Mater Chem 2007;17(43):4611- 8 .

[42] Fenelonov V, Derevyankin A, Okkel L, Avdeeva L, Zaikovskii V, Moroz EM, et al. Structure and texture of filamentous carbons produced by methane decomposition on Ni and Ni-Cu catalysts. Carbon 1997;35(8):1129-40.

[43] Ledoux M, Pham-Huu C. Carbon nanostructures with macroscopic shaping for catalytic applications. Catal Today 2005;102-103:2-14.

[44] Avdeeva L, Goncharova O, Kochubey D. Coprecipitated Nialumina and $\mathrm{Ni} \mathrm{Cu}$-alumina catalysts of methane decomposition and carbon deposition. II Evolution of the catalyst in the reaction. Appl Catal A: General 1996;141(1):117-29.

[45] Pham-Huu C, Ledoux M-J. Carbon nanomaterials with controlled macroscopic shapes as new catalytic materials. Top in Catal 2006;40(1-4):49-63.

[46] Louis B, Vieira R, Carvalho A, Amadou J, Ledoux MJ, Pham-Huu C. Carbon nanofibers grown over graphite supported $\mathrm{Ni}$ catalyst: relationship between octopus-like growth mechanism and macroshapings. Topics Catal 2007;45(1- 4):75-80.

[47] Pham-Huu C, Vieira R, Louis B, Carvalho A. About the octopus-like growth mechanism of carbon nanofibers over graphite supported nickel catalyst. J Catal. 2006;240(2):194202.

[48] Chen D, Christensen KO, Ochoa-Fernandez E, Yu Z, Total B, Latorre N, et al. Synthesis of carbon nanofibers: effects of $\mathrm{Ni}$ crystal size during methane decomposition. J Catal 2005;229(1):82-96.

[49] Dupuis A-C. The catalyst in CCVD in carbon nanotube-a review. Prog Mater Sci 2005;50(8):929-61.

[50] Toebes ML, Bitter JH, Van Dillen AJ, De Jong KP. Impact of the structure and reactivity of nickel particles on the catalytic growth carbon nanofibers. Catal today 2002;76(1):33-42.

[51] Anderson PE, Rodriguez NM. Influence of the support on the structural characteristics of carbon nanofibers produced from the metal-catalyzed decomposition of ethylene. Chem mater 2000;12(3):823-30.

[52] Lund CRF. Nickel catalyst deactivation in the steam-carbon reaction. J Catal 1985;95(1):71-83.

[53] Matos J, Brito J, Laine J. Activated carbon supported Ni-Mo: effect of pretreatment and composition on catalyst reducibility and on ethylene conversion. Appl. Catal. A: General 1997;152(1):27-42.
[54] Tomita A, Sato N, Tamai Y. Hydrogenation of carbons catalyzed by Nickel, Platinum and Rhodium. Carbon 1974;12(2):143-9.

[55] Figueiredo JL, Bernardo CA, Chludzinski JJ, Baker RTK The reversibility of filamentous carbon growth and gasification. J Catal 1988;110(1):127-138.

[56] Lund C. Staged carbon gasification with Nickel catalyst. Carbon 1987;25(3): 337-41.

[57] Baker RTK, Sherwood RD. Catalytic gasification of graphite by Nickel in various gaseous environments. J Catal 1981;70(1):198-214.

[58] Baker RTK, Sherwood RD, Derouane EG. Further studies of the Nickel/graphite-hydrogen system. J Catal 1982;75(2):382-95.

[59] Baker RTK, Sherwood RD. Catalytic action of iron on graphite in a hydrocarbon/steam environment. J Catal. 1985;95(1):101-7.

[60] Tomita A, Tamai Y. Optical microscopic study on the catalytic hydrogenation of graphite. J Phys Chem. 1974;78(22):2254-8.

[61] Nishiyama Y, Tamai Y. Deposition of carbon and its hydrogenation catalyzed by nickel. Carbon. 1976 ;14(1):13-17

[62] Baker RTK. In situ electron microscopy studies of catalyst particle behavior. Catal Rev-Sci Eng 1979; 19(2):161-209.

[63] Wigmans T, van Doorn J, Moulijn J. Deactivation of nickel during gasification of activated carbon, studied by X-ray photoelectron spectroscopy. Surf Sci 1983;135(1-3):532-52.

[64] Anton R. In situ transmission electron microscopy study of the growth of Ni nanoparticles on amorphous carbon. J Mater Res 2005;20(7):1837-43.

[65] Anton R. On the reaction kinetics of $\mathrm{Ni}$ with amorphous carbon. Carbon 2008;46(4):656-62.

[66] Haydar S, Moreno-Castilla C, Ferro-García MF, CarrascoMarin F, Rivera-Utrilla J, Perrard A, et al. Regularities in the temperature-programmed desorption spectra of $\mathrm{CO}_{2}$ and $\mathrm{CO}$ from activated carbons. Carbon 2000;38(9): 1297-308.

[67] Baker RTK. Metal catalyzed gasification of graphite. In: Figueiredo JL, Moulijn JA, editors. Carbon and coal gasification, NATO ASI Series No. 105. Dordrecht: Springer; 1986; pp. 231-68

[68] Baker RTK, Harris P, Thomas R. Direct observation of particle mobility on a surface in a gaseous environment. Surf Sci 1974;46(1):311-6.

[69] Baker RTK. The relationship between particle in motion on a graphite surface and Tammann temperature. J Catal 1982;78:473-6.

[70] Derbyshire F, Presland A, Trimm D. The formation of graphite films by Precipitation of Carbon from Nickel Foils. Carbon 1972;10(1):114-5.

[71] Omori M, Hirai T, Yajima S. Electron microscope observations of carbon layers around iron particles dispersed in a glasslike carbon matrix. Carbon 1974;12(4):474-6

[72] Nakano H, Nakamura J. Carbide-induced reconstruction initiated at step edges on Ni (111). Surf Sci 2001;482485(1):341-5

[73] Zdansky EO, Nilsson A, Martensson N. CO-induced reversible surface to bulk transformation of carbidic carbon on $\mathrm{Ni}$ (100). Surf Sci Lett 1994;310:L583-8.

[74] Alstrup I, Chorkendorff I, Ullmann S. Interaction of hydrogen with carbidic carbon on $\mathrm{Ni}$ (100). Surf Sci 1993;293(3):133-44.

[75] Nakano H, Ogawa J, Nakamura J. Growth mode of carbide from $\mathrm{C} 2 \mathrm{H} 4$ or CO on Ni(111). Surf Sci 2002;514(1-3):25660 . 
[76] Smith M, Sinharoy S, Levenson L. Thermal decomposition of nickel carbide: an Auger lineshape study. J Vac Sci Technol 1979;16(2):462-5.

[77] Lamber R, Jaeger N, Schulz-Ekloff G. Electron microscopy study of the interaction of $\mathrm{Ni}, \mathrm{Pd}$, and $\mathrm{Pt}$ with carbon. 1 . Nickel catalyzed graphitization of amorphous carbon. Surf Sci 1988;197(3):402-14.

[78] Krivoruchko O, Zaikovskii VA. New phenomenon involving the formation of liquid mobile metal-carbon particles in the low-temperature catalytic graphitisation of amorphous carbon by metallic Fe, Co and Ni. Mendeleev Comm 1998;3:97-100.

[79] Gur'yanova O, Kukovitsky E, L'vov S, Sainov N, Shustov VA. Electron diffraction investigation of catalytic particles at the tips of carbon nanotubes. Phys Sol State 2002;44(3):4734.

[80] Ermakova M, Ermakov D. $\mathrm{Ni} / \mathrm{SiO}_{2}$ and $\mathrm{Fe} / \mathrm{SiO}_{2}$ catalysts for production of hydrogen and filamentous carbon via methane decomposition. Catal Today 2002;77(3):225-35.

[81] Ermakova M, Ermakov D, Plyasova L, Kuvshinov G. XRD studies of evolution of catalytic nickel nanoparticles during synthesis of filamentous carbon from methane. Catal Lett 1999;62(2-4):93-7.

[82] Takenaka S, Ogihara H, Otsuka K. Structural Change of Ni Species in $\mathrm{Ni} / \mathrm{SiO}_{2}$ Catalyst during Decomposition of Methane. J Catal 2002;208(1):54-63.

[83] Krishnankutty N, Vannice M. The effect of pretreatment on $\mathrm{Pd} / \mathrm{C}$ catalyst. 1. Adsorption and absorption properties. J Catal 1995;155(2):312-26.

[84] Krishnankutty N, Li J, Vannice M. The effect of Pd precursor and pretreatment on the adsorption and absorption behavior of supported $\mathrm{Pd}$ catalysts. Appl Catal A: General 1998;173(2):137-44.
[85] Gandia LM, Montes M. Effect of thermal treatments on the properties of Nickel and Cobalt activated-charcoal-supported catalyst. J Catal. 1994;145(2): 276-88.

[86] McCarty J, Wise H. Hydrogenation of surface carbon on alumina-supported nickel. J. Catal 1979;57(3):406-16.

[87] Abildpedersen F, Lytken O, Engbak J, Nielsen G, Chorkendorff I, Norskov J. Methane activation on Ni(111): Effects of poisons and step defects. Surf Sci 2005;590(23):127-37.

[88] White SJ, Woodruff DP, Holland BW, Zimmer RS. A LEED study of the $\operatorname{Si}\{100\}(1 \times 1) \mathrm{H}$ surface structure. Surf. Sci. 1978;74:34-46.

[89] Bengaard HS, Nørskov JK, Sehested JS, Clausen BS, Nielsen LP, Molenbroek AM, et al. Steam reforming and graphite formation on Ni catalyst. J. Catal 2002;209(2):365-84.

[90] Sinclair R, Itoh T, Chin R. In Situ TEM Studies of MetalCarbon Reactions. Microsc and Microanal 2002;8(4):288304.

[91] Savva PG, Olympiou GG, Costa CN, Ryzhkoz VA, Efstathiou AM. Hydrogen production by ethylene decomposition over Ni supported on novel carbon nanotubes and nanofibers. Catal today 2005;102-103:78-84.

[92] Otsuka K, Abe Y, Kanai N, Kobayashi Y, Takenaka S, Tanabe E. Synthesis of carbon nanotubes on $\mathrm{Ni} /$ carbon-fiber catalysts under mild conditions. Carbon 2004;42(4):727-36. 